\title{
Study of Structural and Electric Properties of the PZT 52/48 Doped With Er ${ }^{+3}$
}

\author{
Jaime Alberto Sanchez Caceres ${ }^{a * \mathbb{D}}$, Carlos Augusto Cardoso Passos ${ }^{a}$, João Victor Soares Chagas ${ }^{a}$ \\ Raoni Caetano Barbieri ${ }^{a}$, Rodolpho Toniato Corteletti ${ }^{a}$ \\ aPrograma de Pós-Graduação em Engenharia Mecânica, Universidade Federal do Espírito Santo, \\ Vitória, ES, Brasil
}

Received: February 10, 2019; Revised: June 12, 2019; Accepted: September 08, 2019.

\begin{abstract}
The scientific community has shown a growing interest in relating to the ferroelectric materials and it has made an effort to develop them. Among these several ferroelectric materials, we proposed to investigated $\mathrm{Pb}(\mathrm{ZrTi}) \mathrm{O}_{3}$ doped with distinct $\mathrm{Er}^{+3}$ concentrations. Our aim was to investigate how the erbium affects the PZT electrical properties. To determine the ideal sintering temperature of our ceramic samples, the dilatometry tests were performed. These results have showed that the erbium caused a change in sample densities $(91.9 \%<\rho<99.0 \%)$ as compared to undoped PZT sample. Furthermore, the X-ray diffraction results indicated that all samples are monophasic and peaks are indexed to tetragonal crystalline structure. According to these also results, there was an increment of the parameter $a$ and a reduction of parameter $\mathrm{c}$ as compared to undoped PZT sample. On the other hand, the average grain size have decreased with the increment of erbium content. The electrical characterization of ours ceramics showed a peculiar ferrelectric-paraeletric phase transition around $390{ }^{\circ} \mathrm{C}$. Finally, the ferroelectric hysteresis measurements for doped samples in site A have revealed that remnant polarization and coercive field values depend on content. Whereas, doped samples in site $\mathrm{B}$, the corresponding values are similar.
\end{abstract}

Keywords: Ferroelectric materials, electrical properties, impedance spectroscopy, dielectric properties.

\section{Introduction}

The ferroelectric materials have attracted intense interest from both scientific and engineering communities because fundamental physics standpoints and their practical applications. Thus, the research about the ferroelectrics remained since their discovery in 1921 and which has continued to current days, as reported by Vasudevan et al. ${ }^{1}$. In this context, in 1954 , there was a great advance in the study of the $\mathrm{PbZr}_{1}$. ${ }_{x} \mathrm{Ti}_{\mathrm{x}} \mathrm{O}_{3}$ compound with $\mathrm{x}=45 \%$ because this composition has presented highest piezoelectric response and coefficient piezoelectric ${ }^{2-4}$.

The properties of PZT ceramics may be modified by addition of dopants. There are three types of additives named isovalent dopants, donor dopants and acceptor dopants. In according to Panda and $\mathrm{Sahoo}^{5}$, by selecting a suitable composition near morphotropic phase boundary (MPB) and suitable dopants, PZTs of high piezoelectric properties can be synthesized. This is, when dopants are introduced to PZT ceramics their electrical characteristics are enhanced. Here, we are concerned with the PZT ceramics which has been added $\mathrm{Er}^{3+}$ into the PZT ceramic.

The PZT compounds are prepared for different processing routines such as co-precipitation ${ }^{6-9}$, hydrothermal synthesis ${ }^{10}$, solid state reaction ${ }^{11}$, molten salt synthesis, sol-gel ${ }^{12}$ and

*e-mail: jcaceres.vix@gmail.com others ${ }^{13,14}$. And as consequence, these synthesis procedures influence the density and microstructure which control the ceramic properties ${ }^{15}$. The conventional sintering process of those ceramics uses powders prepared by solid state reaction (SSR) and requires heat treatment temperatures among 1200 and $1300^{\circ} \mathrm{C}$. However, such high temperatures cause loss of $\mathrm{PbO}$ by volatilization ${ }^{16,17}$. And this results in environmental pollution problems, causes breaking of the desired composition stoichiometry and deteriorates the ceramics properties ${ }^{16,17}$. In this context, Takahashi ${ }^{18}$ sintered $\mathrm{PbZr}_{0.52} \mathrm{Ti}_{0.48} \mathrm{O}_{3}$ ceramic at $800^{\circ} \mathrm{C}$. His results indicated that densities of ceramic are greater than those ceramics made by conventional procedures with high isothermals. Moreover, those results showed that piezoelectric characteristics are sufficient to practical use. Anyway, understanding and control of the microstructure are necessary to improve the physical properties of granular ferroelectrics and their applications ${ }^{19}$.

In this outline present work, we intend to study several factors that contribute or affect the ferroelectric responses of these materials in close relation with their structural characteristics. In particular, we wish to investigate $\mathrm{PbZr}_{0.52} \mathrm{Ti}_{0.48} \mathrm{O}_{3}$ doped with erbium.

\section{Experimental Details}

The lead zirconate titanate $(\mathrm{Zr}: \mathrm{Ti}=52: 48)$ preparation is performed considering the phase diagram in the interface 
region of the morphotropic phase of the two solid solutions $\mathrm{PbZrO}_{3}(\mathrm{PZ})$ and $\mathrm{PbTiO}_{3}(\mathrm{PT})$, as highlighted in Figure 1.The synthesis route to prepare the samples was by the polymer precursor method (Pechini method modified ${ }^{20}$ ). The following reagents were used: Lead Acetate, Titanium Isopropoxide, Zirconium Oxide Dinitrate.

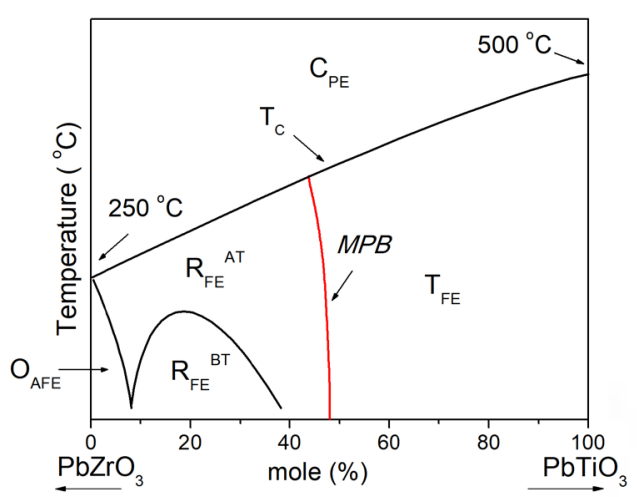

Figure 1. Phase diagram of the $\mathrm{PbTiO}_{3}-\mathrm{PbZrO}_{3}$ system. The line denoted by MPB ("Morphotropic Phase Boundary") separates the ferroelectric tetragonal region $\left(\mathrm{T}_{\mathrm{FE}}\right)$ from the ferroelectric rhombohedral region $\left(\mathrm{R}_{\mathrm{FE}}{ }^{\mathrm{BT}}\right.$ : low temperature rhombohedral modification; $\mathrm{R}_{\mathrm{FE}}{ }^{\mathrm{AT}}$ : high temperature rhombohedral modification). $\mathrm{O}_{\mathrm{AFE}}$ refers to the orthorhombic antiferroelectric region, while the Tc line indicates the Curie temperature behavior separating the FE and AFE phases of the parabolic cubic phase $\left(\mathrm{C}_{\mathrm{PE}}\right)$.

In second step, the PZT precursors was doped with Erbium Oxide. Each precursor was weighted with stoichiometry of final product, that is, $\mathrm{Pb}_{1-\mathrm{x}} \mathrm{Er}_{\mathrm{x}}\left(\mathrm{Zr}_{0.52} \mathrm{Ti}_{0.48}\right) \mathrm{O}_{3}$ and $\mathrm{Pb}\left(\mathrm{Zr}_{0.52} \mathrm{Ti}_{0.48}\right)_{1-\mathrm{x}}$
$\mathrm{Er}_{\mathrm{x}} \mathrm{O}_{3}$ being $\mathrm{x}=0.0,0.5,1.0$ and 3.0 mole percent. All preparation conditions of the PZT ceramic are summarized in Figure 2.

The third step was to submit the resin to two heat treatment in order to eliminate the part organic at $400^{\circ} \mathrm{C}$ and to crystallize at $700{ }^{\circ} \mathrm{C}$ the precursor material ${ }^{21-24}$. This last heat treatment resulted in precursors in powder form. After that, each precursor was pelletized in cylindrical geometry with $7.0 \mathrm{~mm}$ of diameter and submitted to a uniaxial compression of $80 \mathrm{kgf} / \mathrm{cm}^{2}$ for 20 seconds. The density of precursors were equal to $43 \%$ as compared to its theoretical density ( $\rho=8.006 \mathrm{~g} / \mathrm{cm}^{3}$ - card \#33-0784; JCPDS).

To determine the ideal sintering temperature of our ceramic samples ${ }^{25,26}$, the dilatometry tests were performed. The tests were carried out with a Netzsch (DIL 402 PC) dilatometer, with a constant heating rate of $10^{\circ} \mathrm{C} / \mathrm{min}$ under synthetic air flow, in the temperature range of $25^{\circ} \mathrm{C}$ to a temperature that does not reach the melting point of material. Finally, each pellet was introduced in furnace and sintered with isothermals among $840^{\circ} \mathrm{C}$ to $980{ }^{\circ} \mathrm{C}$. The density of the sintered samples was determined by the Archimedes method using distilled water.

Our samples were characterized by X-ray powder diffraction (XRD), Scanning Electron Microscopy (SEM), Transmission Electron Microscopy (TEM), Impedance Spectroscopy techniques. The XRD measurements was performed using a Rigaku Rotaflex RU200B automatic diffractometer, copper $\mathrm{K} \alpha$ radiation with the parameters (50KV, $100 \mathrm{~mA}, 1.5405 \AA$ ). Scanning electron microscopy (SEM-FEG) and transmission electron microscopy (TEM) were used to analyze the morphology of the powders and the ceramics through a scanning electron microscope (SEM-FEG,

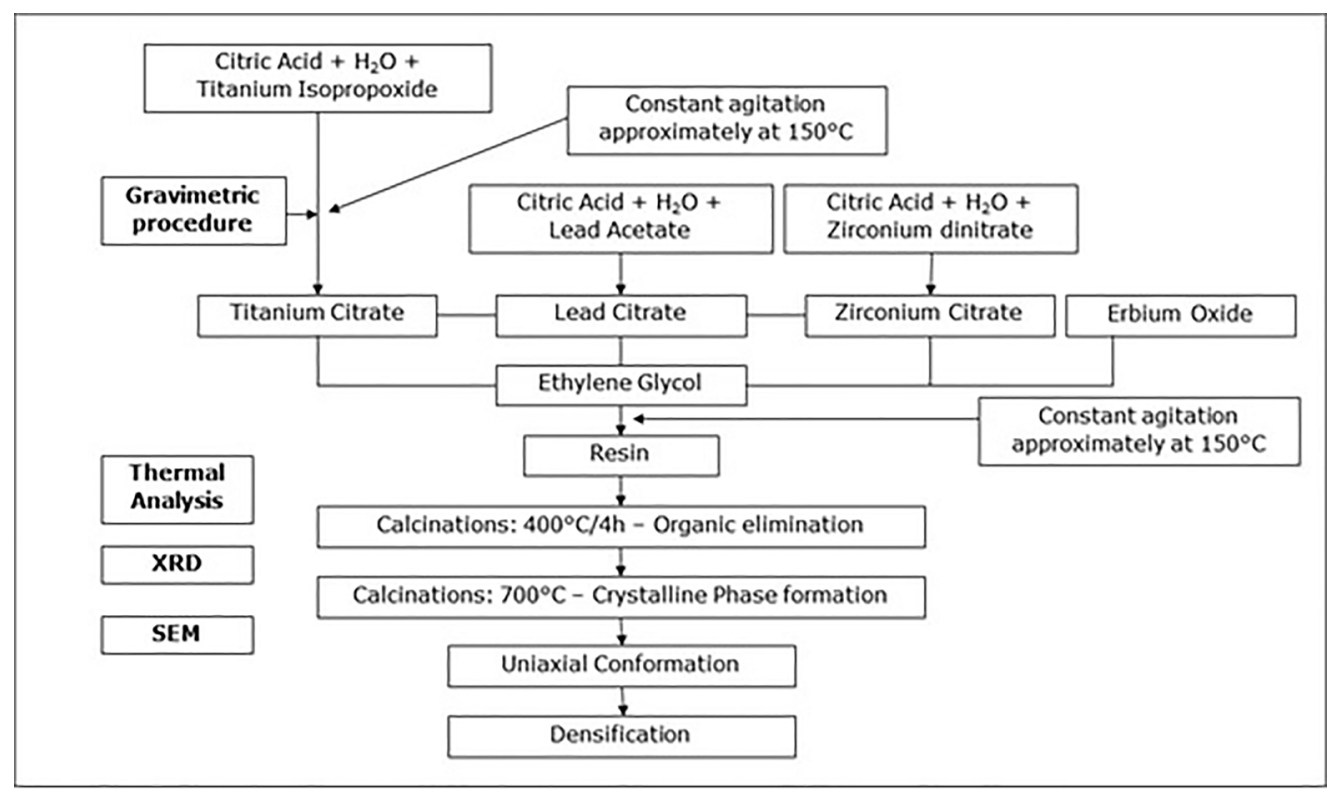

Figure 2. Flowchart for obtaining PZT doped with erbium via the Polymeric Precursor Method. 
Supra 35 Zeiss) and transmission electron microscopy (TEM - Philips CM 120). The aim was to evaluate the degree of densification of the materials, as well as the average size of the samples grains by applying the method of intercepts ${ }^{27}$, following the standards of the American Society for Testing and Materials (ASTM 152).

The samples were submitted to dielectric studies using the impedance spectroscopy technique. The measurements were carried out with a Solartron SI 1260 impedance analyzer, over a wide range of frequencies, from $f=10^{2} \mathrm{~Hz}$ to $f=1$ $\mathrm{MHz}(f=\omega / 2 \pi$ is the linear frequency), and from room temperature up to $550^{\circ} \mathrm{C}$ with intervals $20^{\circ} \mathrm{C}$. The entire process was computer controlled. The samples in cylindrical geometry had their faces coated with a solution of platinum (to perform the function of electrodes), and later taken to the greenhouse release the solvent.

\section{Results and Discussion}

\subsection{Precursor Characterization}

As mentioned in Section 2, our precursor materials were submitted to two heat treatments (calcination process). The obtained powders were then analyzed by X-ray powder diffraction to evaluate crystalline phase formations. The XRD results of the precursors are displayed in Figure 3. It is possible to observe that all peaks are indexed to PZT phase without any formation of secondary phase, if it takes account that second temperature of calcination was $700^{\circ} \mathrm{C}$. Thus, Pechini method confirms to be a good design of the used calcination processes.

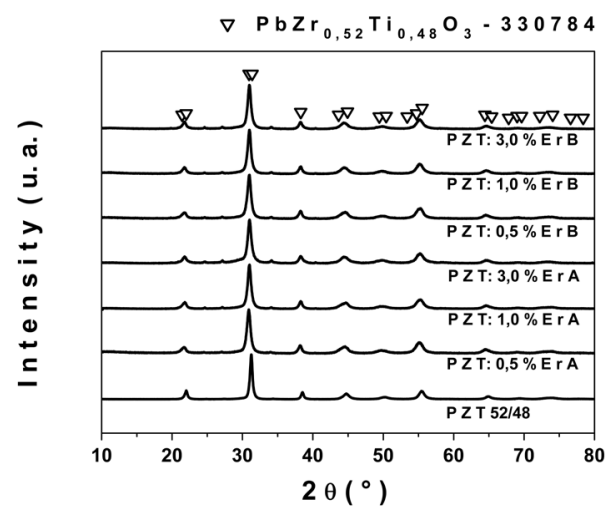

Figure 3. X-ray diffraction patterns of the precursors prepared at $700{ }^{\circ} \mathrm{C}$ with different Er concentration.

In following, microscopy analysis were carried out in all powder precursors. The images were made in SEM-FEG and TEM microscopes. The micrographs revealed that the particles are nanometric size and form agglomerated during calcination stage, as can to be seen in Figures $4 a, 4 b, 5 a$ and $5 \mathrm{~b}$. In our opinion, the agglomerates of particles are due to coalescence process.
To downsize these agglomerates, we have submitted these precursor to milling with zirconium spheres for 24 hours. Here our aim was to obtain a ceramic with high density. After that, these precursors were analyzed by scanning electronic and transmission electronic microscopes again. In Figures $4 c$, $4 \mathrm{~d}, 5 \mathrm{c}$ and $5 \mathrm{~d}$, the micrographs indicate those agglomerates were breaking. Moreover, these figures reveal that particles have size less than $30 \mathrm{~nm}$.

\subsection{Sample Characterization}

To determined sintering temperature, we submitted all precursors to dilatometric test. The results are summarized in Figure 6. For the precursor without doping, we found that the temperature for maximum retraction was $896^{\circ} \mathrm{C}$. Therefore, this precursor was sintered above that temperature to ensure the maximum density of PZT 52/48 ceramic. This same analysis was applied on the others precursors with different erbium concentrations. The temperatures of maximum retraction $\left(\mathrm{T}_{\text {rect }}\right)$ are displayed in the Table 1.

As considering the results the dilatometer experiments, our samples were produced under optimal sintering conditions. All the sintering temperatures are described on the Table 1. These undoped samples PZT and Er-doped PZT were also analyzed by density measurements. The results show that the erbium causes a change in sample densities as compared to undoped PZT sample. For PZT samples with substitution in site $\mathrm{A}$, the density is maximum for $\mathrm{x}=0.5 \%$. In the case of PZT with substitution in site $\mathrm{B}$, the density is maximum for $\mathrm{x}=1.0 \%$, as also can be seen in Table 1 . In addition, we can observe that PZT:0.5\%ErA and PZT:0.5\%ErB samples have similar densities. This can be associated to the cell volumes are approximated equals.

The high density of the ceramics, above $90 \%$, can be justified by the method used for preparation of samples (Pechini method). This technique provides particle size of the order of $30 \mathrm{~nm}$. This then allows a high densification. Powders with such characteristics imply higher defect density and, therefore, higher solid state reactivity by ion diffusion.

The obtained samples were submitted to X-ray powder diffraction in range from $20^{\circ}$ to $80^{\circ}$, as can be seen in Figure 7. The XRD spectra are quite similar and our analysis confirms that the samples are monophasic and peaks are correspond to tetragonal crystalline structure. In our opinion, the Er ion replace $\mathrm{Pb}$, Ti and $\mathrm{Zr}$ sites. Moreover, the XRD examination by Rietveld refinement enabled to calculate lattice parameters as a function of erbium concentration. The samples parameters are listed in the Table 2.

According to these results, there was an increment of the parameter $a$ and a reduction of parameter $c$ as compared to undoped PZT sample. The samples A presented cell volume variation lower than samples $\mathrm{B}$ from the concentration $\mathrm{x}=$ $1.0 \%$. These changes are attributed to changes caused by mass differences, electron structure and the radius among $\mathrm{Pb}, \mathrm{Zr}$, Ti and Er ions. 


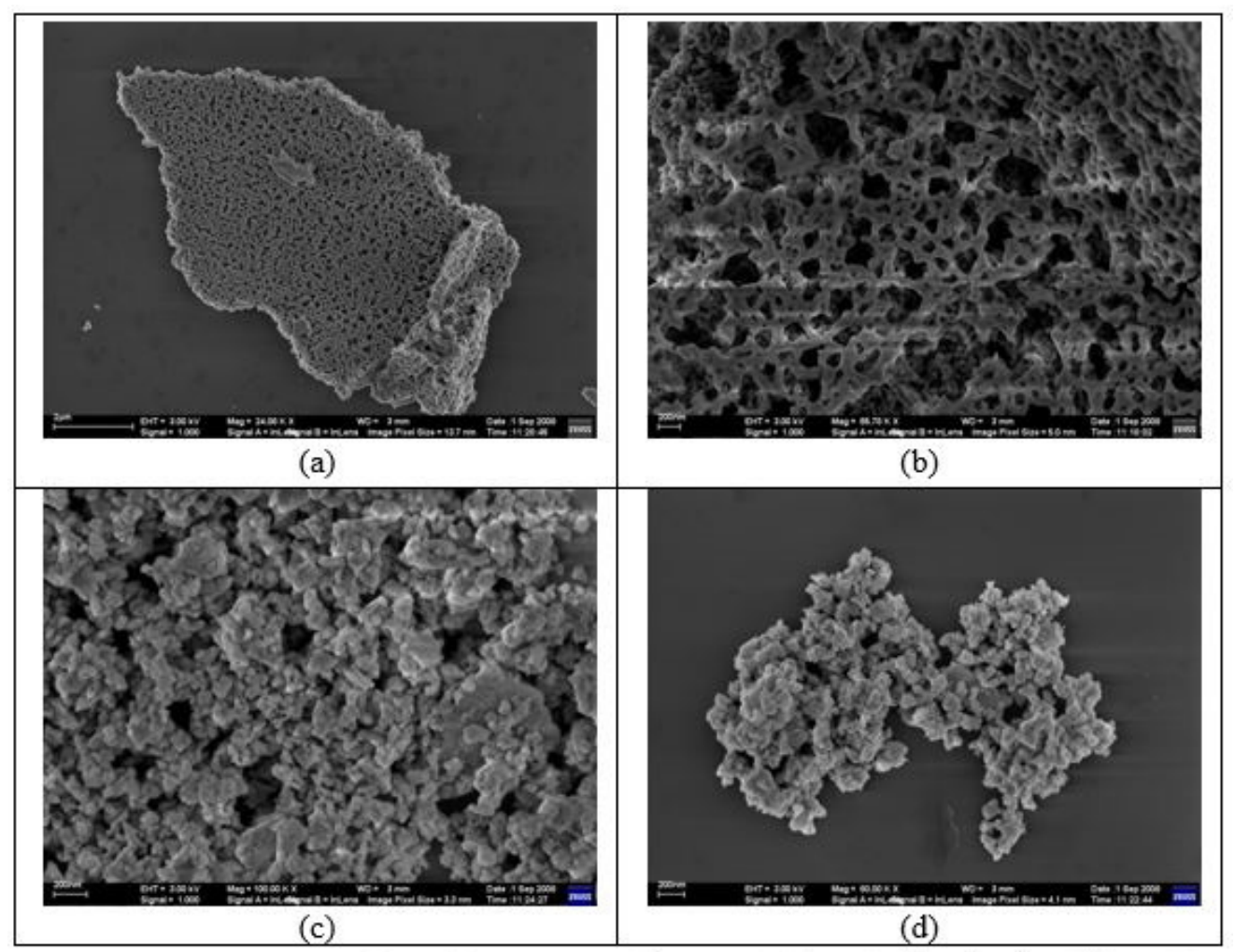

Figure 4. Micrographs of powder precursor before $(a, b)$ and after $(c, d)$ milling with Zirconium sphere.

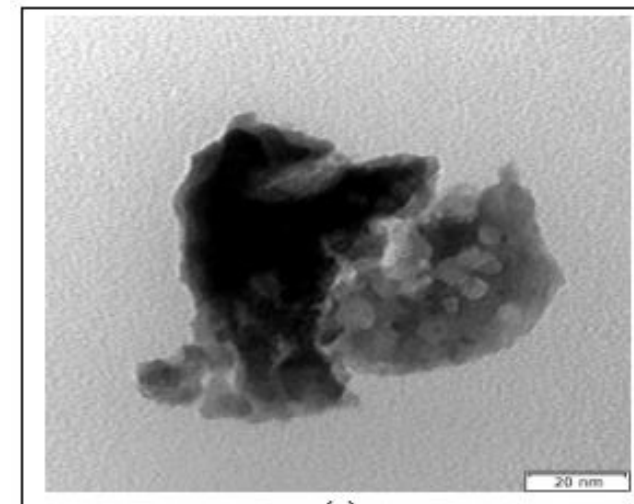

(a)

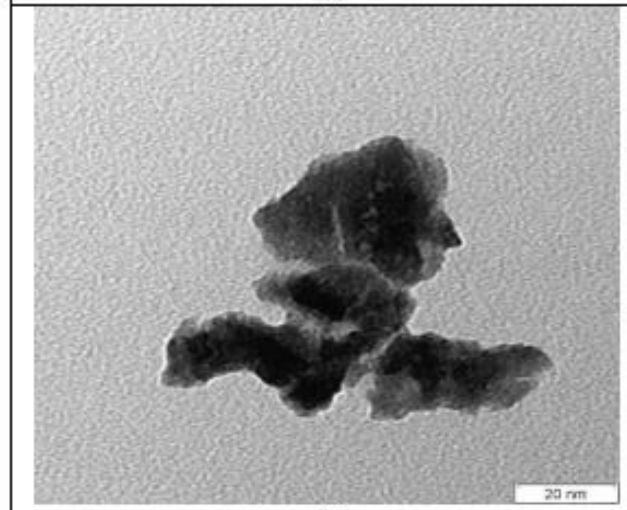

(c)

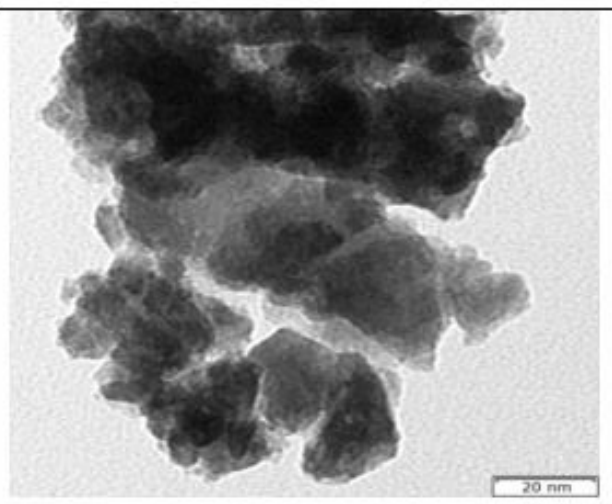

(b)

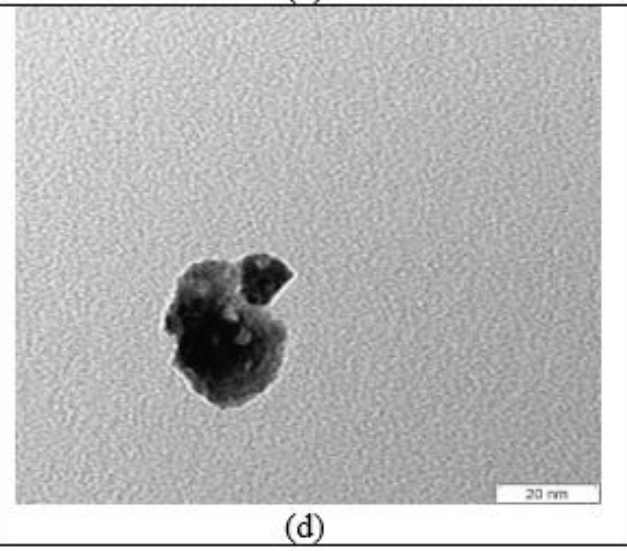

Figure. 5. Electron Transmission Microscopy micrographs of powder precursor before (a, b) and after (c, d) milling with Zirconium spheres. 

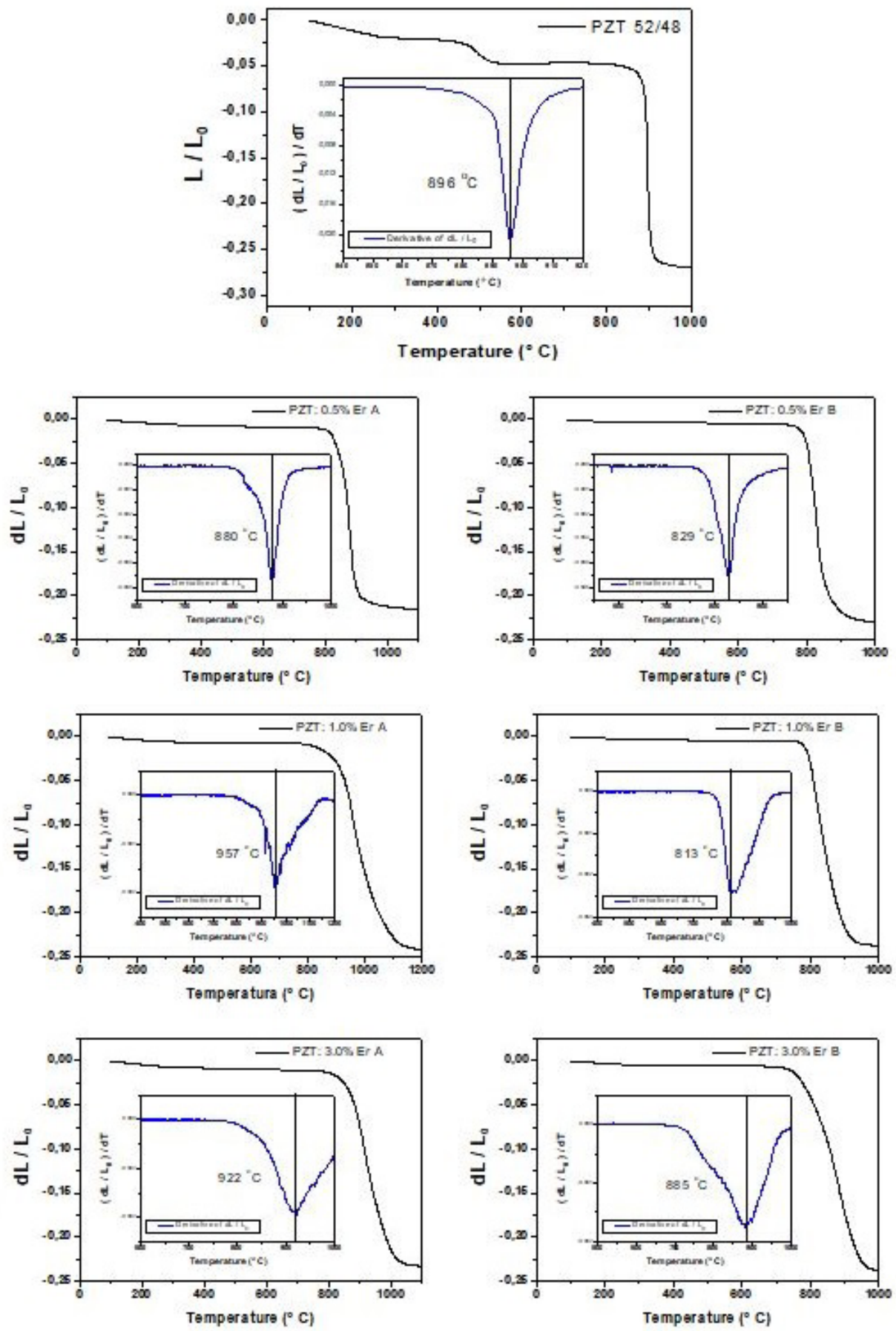

Figure 6. Dilatometric results of all compositions.

We have obtained scanning electron microscopy SEM images all samples. Details of the ceramics grain morphology can be observed in the SEM images in Figures 8, 9 and 10. The image reveals that the ceramic presents low porosity and has a distribution of grain sizes. Using this image and following ASTM standards 152 , we determined average grain size whose value was $(2.01 \pm 0.05) \mu \mathrm{m}$. The same analysis was done for others samples and it can be noted that average grain sizes decreased with increment of erbium concentration. The ceramics PZT:0.5\%ErA, PZT:1.0\%ErA, PZT:3.0\%ErA, PZT:0.5\%ErB, PZT:1.0\%ErB and PZT:3.0\%ErB presented $(1.92 \pm 0.05) \mu \mathrm{m}$ and $(1.75 \pm 0.05) \mu \mathrm{m}(0.54 \pm 0.05) \mu \mathrm{m}$ and $(1.69 \pm 0.05) \mu \mathrm{m}(0.88 \pm 0.05) \mu \mathrm{m}$ and $(0.55 \pm 0.05) \mu \mathrm{m}$, respectively. In our opinion, this behavior may be associated to a grain "pinning" process, that is, low mobility of the grain boundaries during the sintering process, induced by 
Table 1. Values of retraction temperature, sintering temperatures and relative densities of PZT ceramics.

\begin{tabular}{lccc}
\hline Samples & Trect $\left({ }^{\circ} \mathrm{C}\right)$ & Tsintering $\left({ }^{\circ} \mathrm{C}\right)$ & $\rho(\%)$ \\
\hline PZT52/48 & 896 & 910 & 95.6 \\
PZT:0.5\%ErA & 880 & 895 & 98.6 \\
PZT:0.5\%ErB & 829 & 845 & 98.9 \\
PZT:1.0\%ErA & 957 & 975 & 91.9 \\
PZT:1.0\%ErB & 813 & 830 & 99.0 \\
PZT:3.0\%ErA & 922 & 940 & 93.5 \\
PZT:3.0\%ErB & 885 & 900 & 97.5 \\
\hline
\end{tabular}

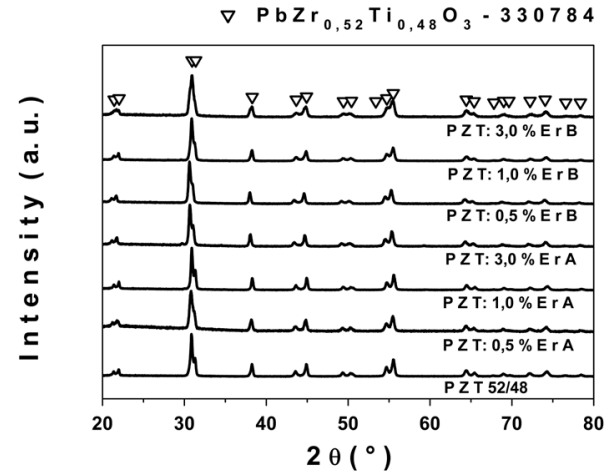

Figure 7. X-ray diffraction patterns of sintered ceramics (all compositions).

the presence of $\mathrm{Er}^{3+}$ ions (substitutional and/or interstitial) on the grain surface.

\subsection{Dielectric Properties}

In Figure 11 shows the permittivity behavior of PZT ceramic as a function of temperature. For undoped PLZT $52 / 48$, from room temperature to $390^{\circ} \mathrm{C}$, the dielectric constant increases initially with rise in temperature. After dielectric constant reaching a maximum at a temperature, dielectric constant decreases with increase in temperature. It can also note that there is a small thermal hysteresis between the values measured for heating and cooling processes. Furthermore, it is also to observe that the dielectric factor $\operatorname{loss}\left(\tan \delta=\varepsilon^{\prime \prime} / \varepsilon^{\prime}\right)$ values close to zero in room temperature.

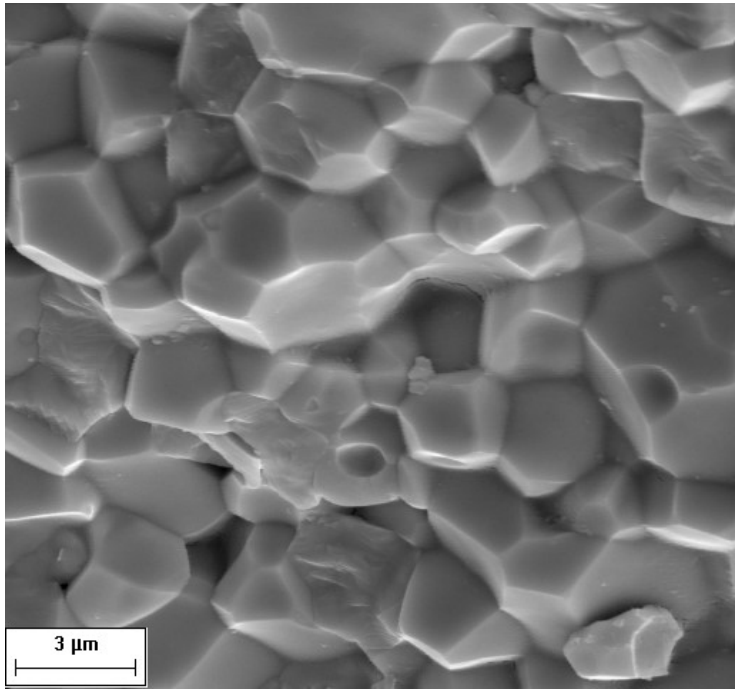

Figure 8. SEM image illustrating the microstructure of the undoped PZT52/48 sample.

The electrical characterization (Figure 12) of others ceramics showed a trend similar, that is, we observed a peculiar ferrelectric-paraeletric phase transition around 390 ${ }^{\circ} \mathrm{C}$ for all compositions. The values of maximum dielectric constant for each composition are given in Table 3. From the quantitative point of view, the ferroelectric parameters (Tc and maximum permittivity values, Table 3 ) are in the range of values reported in the literature for this materia ${ }^{28}$.

Finally, Figure 13 shows the dielectric constant for several frequencies $\left(10^{2}-10^{6} \mathrm{~Hz}\right)$ for PZTE0.5\%ErA sample. The maximum peak position shows no frequency dependence

Table 2. Lattice parameters $a, c$, cell volume, tetragonality and statistical parameters of refinement Rietveld results.

\begin{tabular}{lcccccc}
\hline Amostra & $a(A)$ & $c(A)$ & $V_{\text {cell }}\left(\AA^{3}\right)$ & $c / a$ & $\mathrm{R}_{\text {Bragg }}$ & $\chi_{2}$ \\
\hline PZT $52 / 48$ & $4.0122(7)$ & $4.1556(5)$ & $66.8989(4)$ & $1.0357(3)$ & 3.43 & 2.415 \\
PZT:0.5\%ErA & $4.0323(7)$ & $4.1352(2)$ & $67.0761(1)$ & $1.0255(1)$ & 3.19 & 2.025 \\
PZT:1.0\%ErA & $4.0285(7)$ & $4.1421(5)$ & $67.2245(1)$ & $1.0281(9)$ & 3.51 & 2.166 \\
PZT:3.0\%ErA & $4.0298(1)$ & $4.1334(5)$ & $67.1246(1)$ & $1.0257(1)$ & 3.89 & 1.605 \\
PZT:0.5\%ErB & $4.0339(2)$ & $4,1339(1)$ & $67.2690(9)$ & $1.0247(8)$ & 3.31 & 1.799 \\
PZT:1.0\%ErB & $4.0353(1)$ & $4.1369(6)$ & $67.3651(2)$ & $1.0251(9)$ & 2.51 & 2.136 \\
PZT:3.0\%ErB & $4.0399(1)$ & $4.1272(4)$ & $67.3601(5)$ & $1.0216(1)$ & 3.85 & 1.922 \\
\hline
\end{tabular}




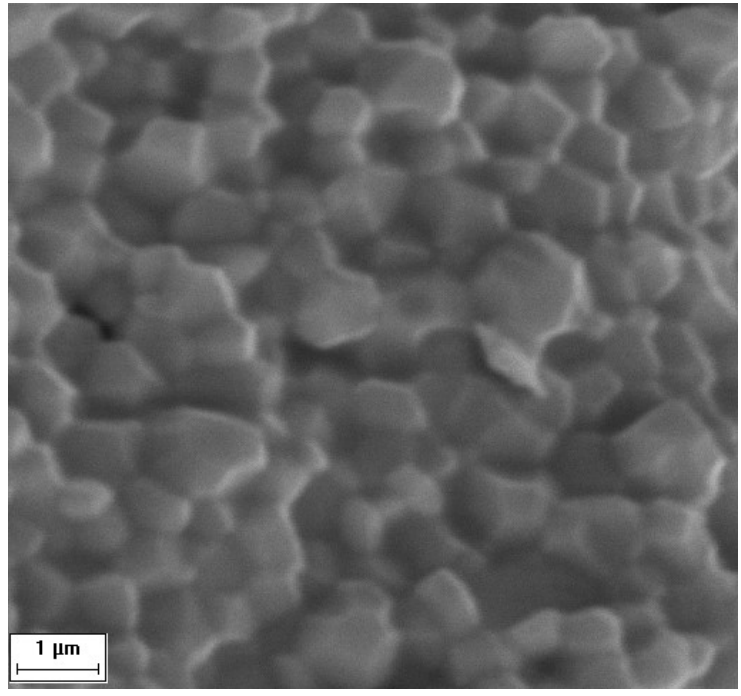

Figure 9. SEM image illustrating the microstructure of a ceramic sample of PZT:1,0\%ErB.

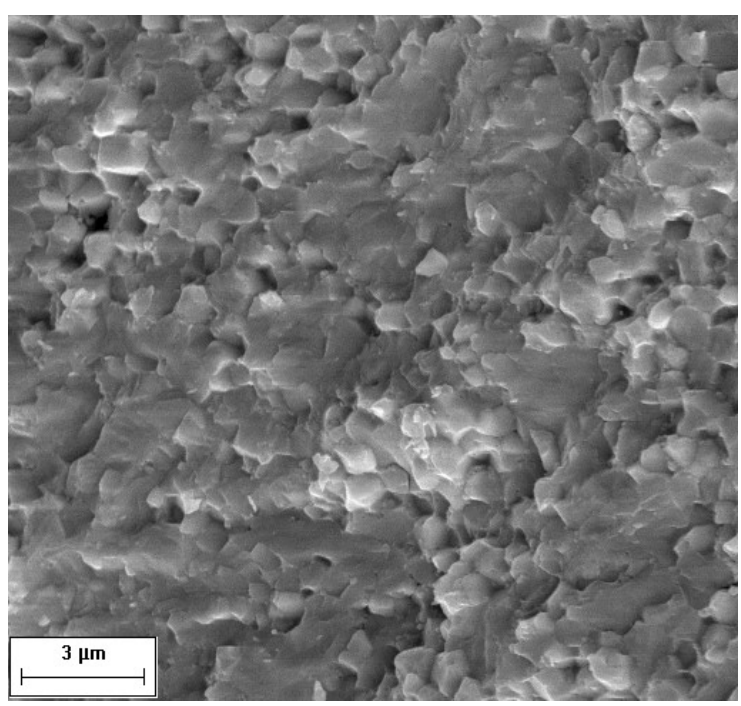

Figure 10. SEM image illustrating the microstructure of a ceramic sample of PZT:3,0\%ErB.

from $10^{4}$ to $10^{6} \mathrm{~Hz}$ (higher frequencies). However, for low frequencies $\left(10^{2}\right.$ and $\left.10^{3} \mathrm{~Hz}\right)$ it is possible to observe the phenomenon dielectric anomaly ${ }^{29}$, but $\varepsilon_{\text {max }}^{\prime}$ values increased. This same behaviour is also observed at others samples.

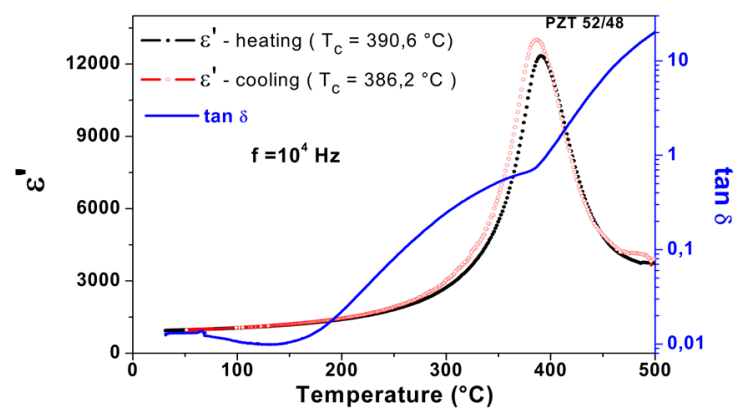

Figure 11. Dependence with temperature of the real part of the permittivity and $\tan \delta\left(\mathrm{f}=10^{4} \mathrm{~Hz}\right.$ ). A small thermal hysteresis is observed in the heating and cooling curves for undoped PZT $52 / 48$ sample.

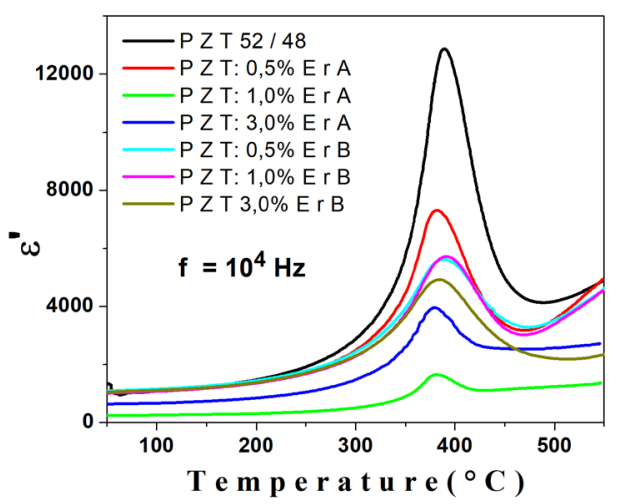

Figure 12. Dependence with the temperature of the real part of the permittivity for all compositions $\left(\mathrm{f}=10^{4} \mathrm{~Hz}\right)$.

The ferroelectric hysteresis measurements were carried out with a home-made modified sawyer-tower circuit and results are displayed on the Figure 14. The frequency used was $60 \mathrm{~Hz}$ for all the samples. The P-E loop of undoped PZT sample indicates remnant polarization $\left(\mathrm{P}_{\mathrm{r}}\right)$ of $6.99 \mu \mathrm{C} / \mathrm{cm}^{2}$ and coercive field $\left(E_{c}\right)$ of $11.31 \mathrm{kV} / \mathrm{cm}$. For doped samples in site $\mathrm{A}, \mathrm{P}_{\mathrm{r}}$ and $\mathrm{E}_{\mathrm{c}}$ values depend on Er contents. Whereas, doped samples in site $\mathrm{B}$, the corresponding values are similar.

The remaining polarization for the non-doped PZT sample is higher than the doped samples with erbium. This can be

Table 3. Curie temperatures and dielectric constants $\left(f=10^{4} \mathrm{~Hz}\right)$.

\begin{tabular}{lcccc}
\hline Samples & $\mathrm{T}_{\text {sintering }}\left({ }^{\circ} \mathrm{C}\right)$ & $\rho(\%)$ & $\mathrm{T}_{\mathrm{C}}\left({ }^{\circ} \mathrm{C}\right)-10^{4} \mathrm{~Hz}$ & $\varepsilon^{\prime} \mathrm{max}-10^{4} \mathrm{~Hz}$ \\
\hline PZT52/48 & 930 & 95,6 & 391 & 12345 \\
PZT:0.5\%ErA & 895 & 98,6 & 382 & 7310 \\
PZT:0.5\%ErB & 845 & 98,9 & 389 & 5617 \\
PZT:1.0\%ErA & 975 & 91,9 & 381 & 1649 \\
PZT:1.0\%ErB & 830 & 99,0 & 391 & 5718 \\
PZT:3.0\%ErA & 940 & 93,5 & 379 & 3955 \\
PZT:3.0\%ErB & 900 & 97,5 & 384 & 4919 \\
\hline
\end{tabular}




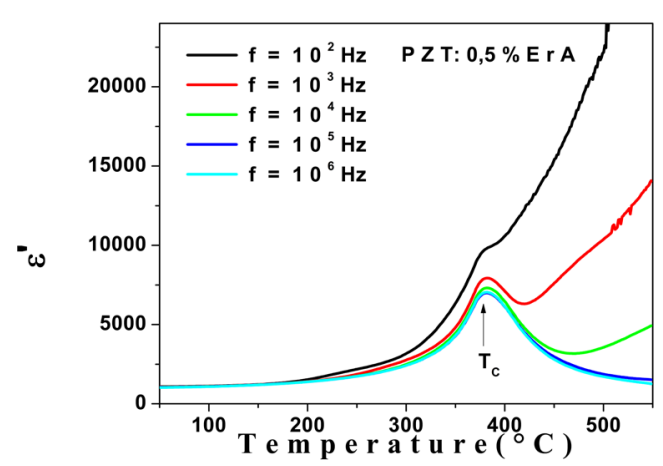

Figure 13. Dependence of dielectric constant with temperature and frequency for PZT: $0.5 \%$ ErA.

explained with the help of lattice parameters. The substitution of the $\mathrm{Er}^{3+}$ ion in site A and site $\mathrm{B}$ causes a shrinkage in the tetragonality of PZT ceramics and an increase in the volume of its unit cell. In our opinion, the $\mathrm{Er}^{3+}$ ion decreased the strength of the electric dipole moments and provoked a charge unbalance (electrons and vacancies). On the other hand, when the $\mathrm{Er}^{3+}$ ions replace the $\mathrm{Pb}^{2+}$ ions, it occurs the formation vacancies in the site $\mathrm{A}$, and this neutralizes the charge unbalance. The replacement of $\mathrm{Er}^{3+}$ ions in the site $\mathrm{B}$ does not create $\mathrm{Pb}$ vacancies enough.

\section{Conclusions}

PZT ceramics pure and doped with Erbium were prepared from the sintering of nanometric powders obtained by the polymer precursors method (Pechini Method). For sintering, temperatures lower than those reported in the literature $(\sim$ $900{ }^{\circ} \mathrm{C}$ ) were used and the obtained ceramic had a relative density of over $92 \%$. The dielectric response of the ceramic sample was obtained by impedance spectroscopy where the thermal dependence was established from $25^{\circ} \mathrm{C}$ to $500^{\circ} \mathrm{C}$, and the ferroelectric-paraelectrical phase transition occurs at temperatures close to $390^{\circ} \mathrm{C}$. The ferroelectric behavior of the ceramic samples was confirmed by the hysteresis loop measured with a Sawyer-Tower circuit. The difference in ferroelectric behavior at sites A and B was identified as the reflection of the process of occupation of the dopant in the structure of the host matrix. In our opinion, the substitution of the $\mathrm{Er}^{3+}$ ion in site A and site B causes a shrinkage in the tetragonality of PZT ceramics and an increase in the volume of its unit cell. This indicates that the $\mathrm{Er}^{3+}$ ion decreased the strength of the electric dipole moments and provoked a charge unbalance. However, if the $\mathrm{Er}^{3+}$ ions replace the $\mathrm{Pb}^{2+}$ ions, it occurs the formation vacancies in the site $\mathrm{A}$, and this neutralizes the charge unbalance. The replacement of $\mathrm{Er}^{3+}$ ions in the site $\mathrm{B}$ does not create $\mathrm{Pb}$ vacancies enough.
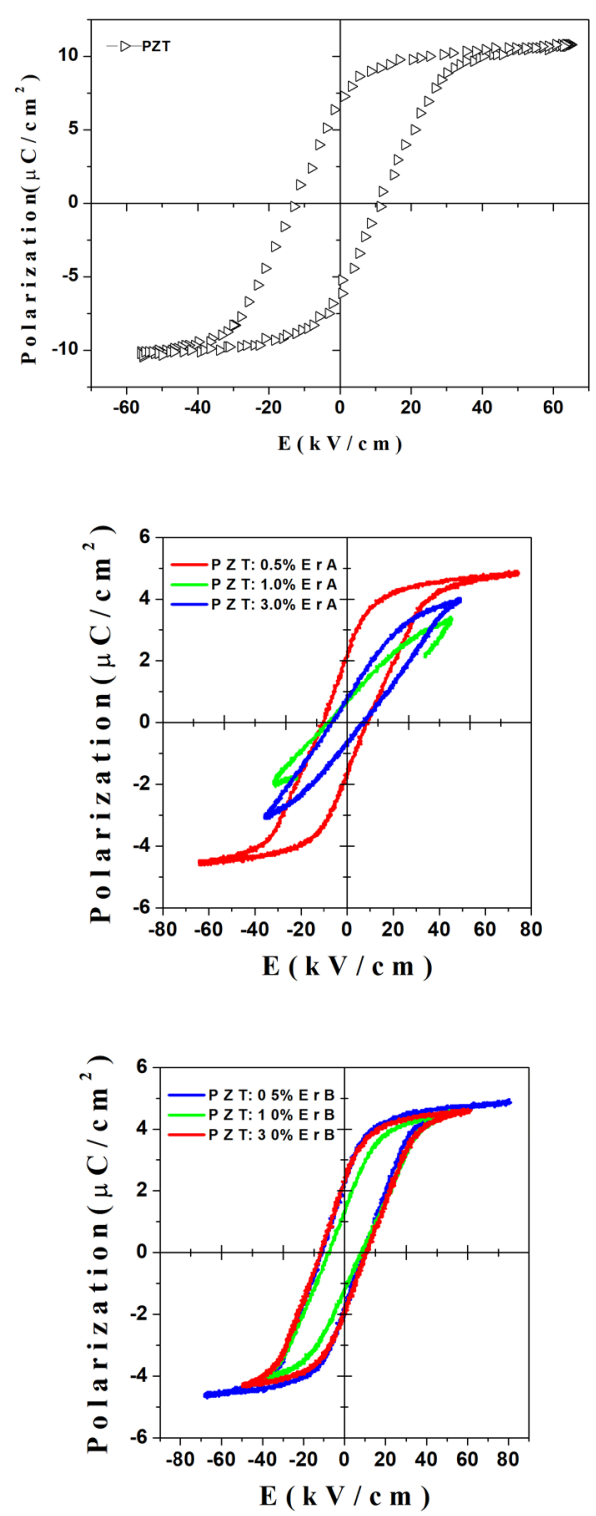

Figure 14. Hysteresis loops at room temperature for all compositions.

\section{Acknowledgment}

The authors gratefully acknowledge financial supports from CAPES, Brazilian research-funding agency, and the Institute of Physic of São Carlos, Universidade de São Paulo.

\section{References}

1. Vasudevan RK, Balke N, Maksymovych P, Jesse S, Kalinin SV. Ferroelectric or non-ferroelectric: Why so many materials exhibit "ferroelectricity" on the nanoscale. Applied Physics Reviews. 2017;4:1-74. 
2. Jaffe B, Cook WR, Jaffe H. Piezoelectric Ceramics. London: Academic Press; 1971

3. Haertling GH. Ferroelectric ceramics: history and technology. Journal of American Ceramic Society. 1999;82(4):797-818.

4. Jaffe B, Roth RS, Marzullo S. Piezoelectric Properties of Lead Zirconate-Lead Titanate Solid-Solution Ceramics. Journal of Applied Physics. 1954;25:809.

5. Panda PK, Sahoo B. PZT to Lead Free Piezo Ceramics: A Review. Ferroelectrics. 2015;474(1):128-143.

6. Kinemuchi Y, Ikeuchi T, Suzuki T, Suematsu H, Jiang W, Yatsui K. Synthesis of nanosize PZT powders by pulsed wire discharge. IEEE Transactions on Plasma Science. 2002;30(5):1858-1862.

7. Hirashima H, Onishi E, Nakagawa M. Preparation of PZT powders from metal alkoxides. Journal of Non-Crystalline Solids. 1990;121(1-3):404-406.

8. Liu C, Zou B, Rondinone AJ, Zhang ZJ. Sol-gel synthesis of free-standing ferroelectric lead zirconate titanate nanoparticles. Journal of American Chemical Society. 2001;123(18):4344-4345.

9. Duran P, Moure C. Sintering at near theoretical density and properties of PZT ceramics chemically prepared. Journal of Materials Science. 1985;20(3):827-835.

10. Mandoki NT, Courtois C, Champagne P, Leriche A. Hydrothermal synthesis of doped PZT powders: sintering and ceramic properties. Materials Letters. 2004;58(20):2489-2493.

11. Kour P, Kumar P, Sinha SK, Kar M. Electrical properties of calcium modified PZT (52/48) ceramics. Solid State Communications. 2014;190:33-39.

12. Sawyer CB, Tower CH. Rochelle salt as a dielectric. Physical Review. 1930;35:269-273.

13. Yamashita K, Chansomphou L, Murakami H, Okuyama M. Ultrasonic micro array sensors using piezoelectric thin films and resonant frequency tuning. Sensors Actuators A: Physical. 2004;114(2-3):147-153.

14. Kim K, Lee S. Integration of lead zirconium titanate thin films for high density ferroelectric random access memory. Journal of Applied Physics. 2006;100:51604-11.

15. Oliveira CA, Longo E, Varela JA, Zaghete MA. Synthesis and characterization of lead zirconate titanate (PZT) obtained by two chemical methods. Ceramics International. 2014;40(1):1717-1722.

16. Zuo R, Li L, Gui Z, Hu X, Ji C. Effects of additives on the interfacial microstructure of cofired electrode-ceramic multilayer systems. Journal of the American Ceramic Society. 2002;85(4):787-793.
17. Mazumder R, Sen A. 'Ultra'-low-temperature sintering of PZT: a synergy of nano-powder synthesis and addition of a sintering aid. Journal of the European Ceramic Society. 2008;28(14):2731-2737.

18. Takahashi S. Sintering $\mathrm{Pb}(\mathrm{Zr}, \mathrm{Ti}) \mathrm{O}_{3}$ ceramics at low temperature. Japanese Journal of Applied Physics. 1980;19(4):771-772.

19. Gajbhiye NS, Pandey PK, George L, Kumar A. Characterization of nanostructured PZT prepared by chemical routes. J Nanosci Nanotech. 2007;7(6):1975-1979.

20. Pechini MU, inventor. Sprague Electric Co., assignee. Method of preparing lead and alkaline earth titanates and niobates and coating method using the same to form a capacitor. US Patent 3330697. 1967 Jul 11

21. Buckner DA, Wilcox PD. Effect of calcining on sintering of lead zirconate-titanate ceramics. American Ceramic Society Bulletin. 1972;51:218-222.

22. Webster AH, Weston TB, Bright NFH. Effect of PbO deficiency on the piezoelectric properties of lead zirconate titanate. Journal of the American Ceramic Society. 1967;50(9):490-491.

23. Crumm AT, Halloran JW. Fabrication of microconfigured multicomponent ceramics. Journal of the American Ceramic Society. 1998;81(4):1053-1057.

24. Lee WH, Tseng T, Hennings DFK. Effects of calcination temperature and $\mathrm{A} / \mathrm{B}$ ratio on the dielectric properties of $(\mathrm{Ba}, \mathrm{Ca})(\mathrm{Ti}, \mathrm{Zr}, \mathrm{Mn}) \mathrm{O}_{3}$ for multilayer ceramic capacitors with nickel electrodes. Journal of the American Ceramic Society. 2000;83(6):1402-1406.

25. Rao KRM, Rao AVP, Komameni S. Reactive PZT precursor powder by coprecipitation. Materials Letters. 1996;28(4-6):463-467.

26. Fang J, Wang J, Ng SC, Gan LM, Chew CH. Synthesis and characterization of ultrafine lead zirconate powders. Ceramics International. 1998;24(7):507-513.

27. Mendelson MI. Average grain size in the polycrystalline ceramics. Journal of the American Ceramic Society. 1969;52(8):443-446.

28. Zhao Z, Buscaglia V, Viviani M, Buscaglia MT, Mitoseriu L, Testino A, et al. Grain-size effects on the ferroelectric behavior of dense nanocrystalline $\mathrm{BaTiO}_{3}$ ceramics. Physical Review B 2004;70:024107.

29. Jiang Q, Cui XF, Zhao M. Size effects on Curie temperature of ferroelectric particles. Applied Physics: A. 2004;78:703-704. 